MATEC Web of Conferences 26,02004 (2015)

DOI: $10.1051 /$ matecconf/ 20152602004

(C) Owned by the authors, published by EDP Sciences, 2015

\title{
Gemstone Grinding Process Improvement by using Impedance Force Control
}

\author{
Chumpol Hamprommarat ${ }^{1, a}$, Anan Sutapun ${ }^{1, b}$, Viboon Sangveraphunsiri ${ }^{1, c}$ \\ 1 Department of Mechanical Engineering, Faculty of Engineering, Chulalongkorn University,
}

254 Phayathai Road, Pathumwan, Bangkok 10330, Thailand

\begin{abstract}
Chula Automatic Faceting Machine has been developed by The Advance Manufacturing Research Lab, Chulalongkorn University to support Thailand Gems-Industry. The machine has high precision motion control by using position and force control. A contact stiffness model is used to estimate grinding force. Although polished gems from the Faceting Machine have uniform size and acceptable shape, the force of the grinding and polishing process cannot be maintain constant and has some fluctuation due to indirect force control. Therefor this research work propose a new controller for this process based on an impedance direct force control to improve the gemstone grinding performance during polishing process. The grinding force can be measured through motor current. The results show that the polished gems by using impedance direct force control can maintain uniform size as well as good shape and high quality surface.
\end{abstract}

\section{Introduction}

Thailand Gems-Industry has been the primary top classified as the highest profitable successfulness. The market need for large amounts but skill labor of humanbeing could not able enough produce for the requirement. Thus, The Advance Manufacturing Research Lab, under The Regional Center of Robotics Technology, Chulalongkorn University, would highly response in research designs and built the CU Automatic Faceting Machine [1] to use in-house facilities. Besides the development of the machine structure, we also concentrate on the development of controllers suitable for the gem grinding and polishing process which has been predefined for our automatic faceting machines. The main objectives for the computerized controller are uniform size and quality of multi-stone grinding and polishing process. We can achieve with superb outcomes compare to manual process. This development is our $3 \mathrm{rd}$ generation of the automatic faceting machine in order to improve grinding performance by using direct force control. Without and force sensor, due to high price and hard to maintenance, the grinding force can be measured through motor current instead. A new controller for the grinding and polishing process is based on an impedance direct force control.

Our previous controller, the 1st generation machine had high precision motion control by using conventional PID control. Because of no force information in the controller loop, the polishing process consume long polishing times. To improve this, the 2nd generation controller, force information is added to the controller loop indirectly based on a contact stiffness model [1]. The contact stiffness model is used to estimate grinding force. Although polished gems from the Faceting Machine have uniform size and acceptable shape, the force of the grinding and polishing process cannot be maintain constant and has some fluctuation due to indirect force control. It also affects the quality of gems such as cracking and scratching. Then in this paper will propose the new controller, 3rd generation controller, based on impedance force control by using current feedback from the motor to estimate grinding force or torque reacting at the gemstones contact to the grinding wheel.

\section{Chula Automatic Faceting Machine}

Structure of the Chula Automatic Faceting Machine, as show in Fig.1 (left), was designed by considering all the control parameter that effect on the shapes, facets and sizes of gems. The control parameters are Elevation Angle, Index Angle, and Depth of Cut as show in Fig.1 (right) which can be represented in XYZ-axis of the Chula Automatic Faceting Machine. The X-axis is the Elevation Angle control which specify the facet of gem. The Y-axis is the Index Angle which is specified how many grinding faces of gem by divided index angle. And Z-axis control Depth of Cut and Cutting Speed which is

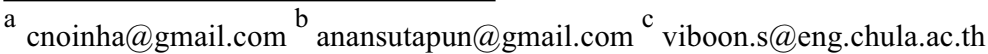


specified size of gem. Due to the quality of shape and size of gems, the steady-state error must be minimized.
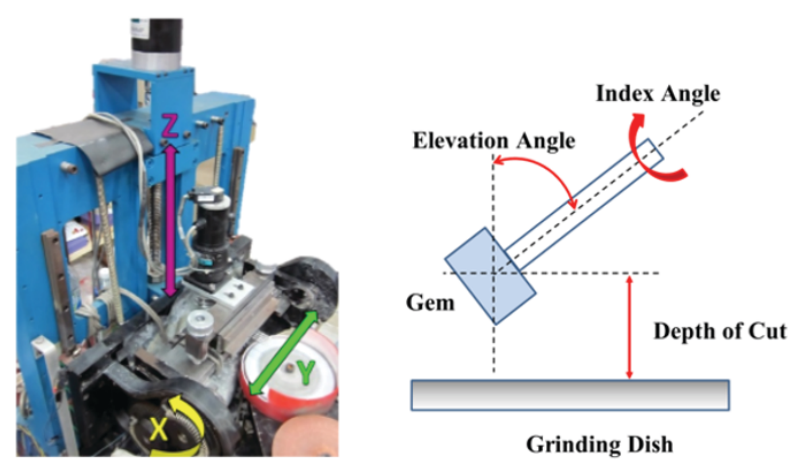

Figure 1. The Chula Automatic Faceting Machine

In 3-Control Parameters, the Depth of Cut and Cutting Speed in Z-axis is the most important because it not only effect on the shape of the outcome but also effect on gem quality as well, no cracking and no scratching. Therefor

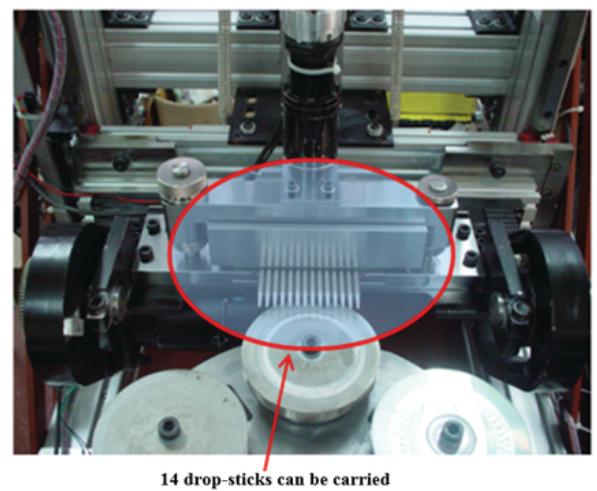

Figure 2. The torque transmission from the motor to gemstones

\section{Control Block Diagram}

The 3rd generation controller or the direct force control base on impedance control is used as show in Fig 3. More detail can be consulted in [3]. It is an impedance control cascased with torque control. The inner loop is a velocity control is closed with a filtered differentation of the encoder signal. This will induce some time delay in the velocity control loop about half of the sampling time. From our experiment, the effect of this time delay has not shown any significant problem within our design bandwidth. Our experiment, the impedance control shown is the block diagram of Fig 3. is just a spring this axis need both accuracy and no excessing force which be described in the next section. And the others need only position control by using PID-Controller.

\section{Force Estimation}

In order to control force in gemstone grinding process, the force at the gemstones must be measured. The reaction force at the gemstones can be estimated by torque from motor transmitted to a ball screw to the gemstones holder as show in Fig.2. Fourteen gems can be cut in any cycles by attached to the end of drop-sticks. The active force in $\mathrm{Z}$-axis, $F$, is proportional to the current, $I$, in the armature coil of the permanent magnet dc servomotor, as show in equation (1), where $n$ is the transmission ratio and $K_{i}$ is the torque constant. The active force can be described as:

$$
F=n K_{i} I
$$

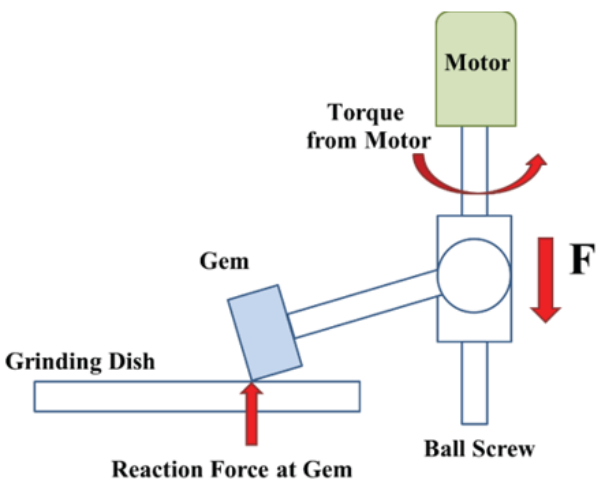

constant. The comparison of the quality of polishing surfaces betwee the 2nd generation controller and 3rd generation controller, based on same cutting conditions, are obviously improved as shown in Fig. 4. Fig. 4(a) compares a single stroke cutting between 3rd and 2nd generation. The surface from the 3rd generation controller are smoother than the surface from the 2nd generation. From Fig. 4(b), with same cutting condition, the quality of the surface from the 3rd generation is also much better than the quality surface from the 2nd generation. And also the polishing time is somewhat faster for the 3rd generation controller.

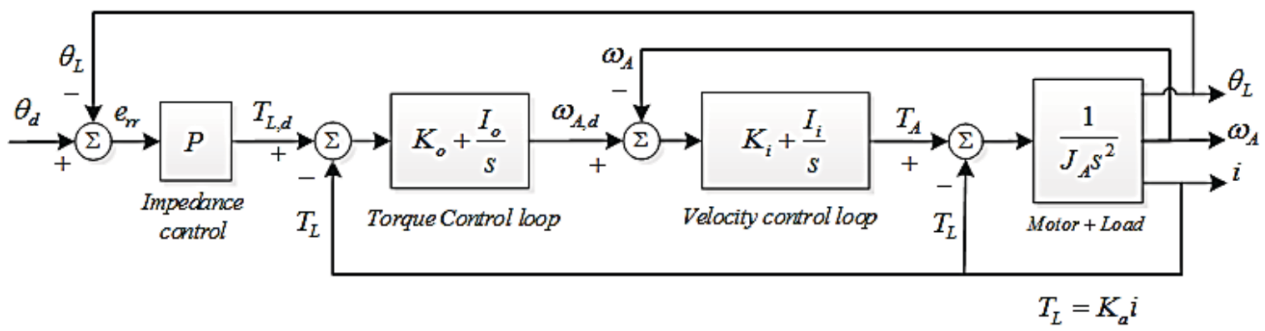

Figure 3. Block diagram of the Impedance Force Control 


\section{Results}

The results show that the polished gems using impedance force control meet the satisfaction level of size, shape and high quality surface as show in Fig.5. The surface quality is far superb compare to manual process and the other two generations. Beside the development of the controller, we also developed a 3-D solid modeling software, CUsolid, based on the Parasolid Kernel [2]. The CU-Solid can used to build and manipulate solids with featurebased modeling concept using Parasolid kernel as the modeler. The CU-Solid has many small software components. Each of components has an individual duty. This software can be used for designing cuting shapes. The parameters obtained from this software can be uploaded and used in the grinding and polishing of the facet machine.

\section{Summary}

We developed the third generation automatic faceting machine, the Chula Automatic Faceting Machine. The new controller base on the impedance direct force control by using current feedback from the motor to estimate grinding force or torque reacting at the gemstones contact to the grinding wheel. The results show that the polished gems by using this new controller can maintain uniform size as well as good shape and high quality surfaces. Especially the surface quality is far superb compare to manual process and the other two generations. With some fine tuning of the parameters in the controller, we believed that the grinding time can be reduced significantly.

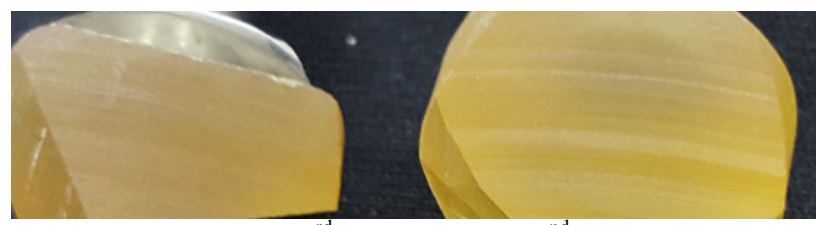

(a) $3^{\text {rd }}$ generation and $2^{\text {nd }}$ generation

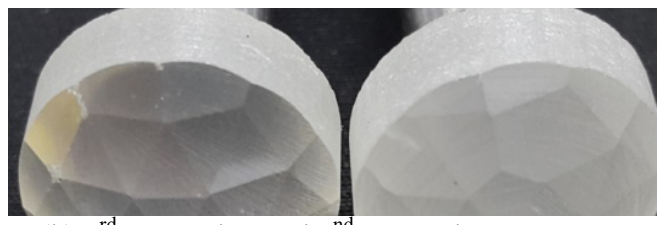

(b) $3^{\text {rd }}$ generation and $2^{\text {nd }}$ generation

Figure 4. Comparison of the polishing surface between the $2^{\text {nd }}$ and the $3^{\text {rd }}$ generation controller
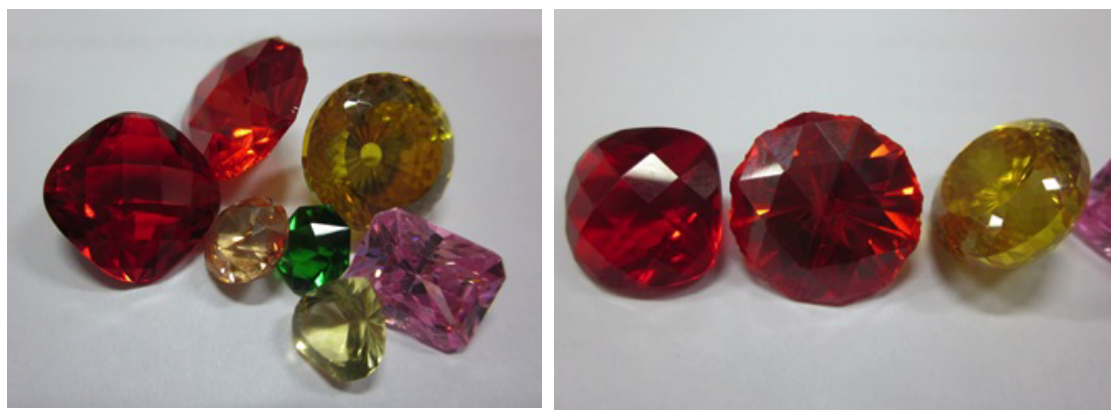

Figure 5. The polished gems by using impedance force control

\section{Acknowledgement}

This research is supported by National Research University Project, Office of Higher Education Commission (WCU-013-HR-57), The 100th Anniversary Chulalongkorn University Fund for Doctoral Scholarship and Regional Center of Robotics Technology, Chulalongkorn University.

\section{References}

1. Kaothong C., Sangveraphunsiri V., "Grinding Force Control of polishing Cubic Zirconia Gem", Applied Mechanics and Materials, Vol. 415 (2013), p. 52-59

2. Viboon Sangveraphunsiri, Kritsana Uttamang, "Development of a 3-D Solid Modeling System Based on the Parasolid Kernel," The 12th International Pacific Conference on Automotive Engineering, IPD-12, Bangkok, Thailand, April 1-4, (2003).

3. H. Vallery, R. Ekkelenkamp, H. van der Kooij, and M. Buss, "Passive and accurate torque control of series elastic actuators," in Proc. IEEE IROS (2007), San Diego, CA, pp. 3534-3538. 